\title{
A Qualitative Multi-Attribute Model for the Selection of the Private Hydropower Plant Investments in Turkey: By Foundation of the Search Results Clustering Engine (Carrot ${ }^{2}$ ), Hydropower Plant Clustering, DEXi and DEXiTree
}

\author{
Burak Omer Saracoglu \\ Orbantepe Mahallesi, Tekel Caddesi, Geziyolu Sokak, 34865 Dragos, Kartal, Istanbul (Turkey) \\ burakomersaracogh@,hotmail.com
}

Received: March 2014

Accepted: February 2016

\section{Abstract:}

Purpose: The electricity demand in Turkey has been increasing for a while. Hydropower is one of the major electricity generation types to compensate this electricity demand in Turkey. Private investors (domestic and foreign) in the hydropower electricity generation sector have been looking for the most appropriate and satisfactory new private hydropower investment (PHPI) options and opportunities in Turkey. This study aims to present a qualitative multiattribute decision making (MADM) model, that is easy, straightforward, and fast for the selection of the most satisfactory reasonable PHPI options during the very early investment stages (data and information poorness on projects).

Design/methodology/approach: The data and information of the PHPI options was gathered from the official records on the official websites. A wide and deep literature review was conducted for the MADM models and for the hydropower industry. The attributes of the model were identified, selected, clustered and evaluated by the expert decision maker (EDM) opinion and by help of an open source search results clustering engine (Carrot ${ }^{2}$ ) (helpful for also comprehension). The PHPI options were clustered according to their installed capacities main property to analyze the options in the most appropriate, decidable, informative, understandable and meaningful way. A simple clustering algorithm for the PHPI options was 
executed in the current study. A template model for the selection of the most satisfactory PHPI options was built in the DEXi (Decision EXpert for Education) and the DEXiTree software.

Findings: The basic attributes for the selection of the PHPI options were presented and afterwards the aggregate attributes were defined by the bottom-up structuring for the early investment stages. The attributes were also analyzed by help of Carrot ${ }^{2}$. The most satisfactory PHPI options in Turkey in the big options data set were selected for each PHPI options cluster by the EDM evaluations in the DEXi.

Originality/value: The recommended DEXi PHPI selection model by the search results clustering engine within a country wise case offered the possibility of easy, meaningful and satisfying continental or worldwide applications for the private investors and the international financial institutions such as the African Development Bank, or the World Bank was the main contribution.

Keywords: Carrot ${ }^{2}$, cluster, clustering, decision, DEX, DEXi, DEXiTree, hydropower, investment, private hydropower plant investments, qualitative scaled attributes, search results clustering engine, Turkey

\section{Introduction}

The overall electricity consumption, the minimum load and the peak load in Turkey has increased since 1990 as shown by the help of the historical data on the Slide 2 in the electronic supplementary files (ESF). The average yearly peak load, the average yearly overall electricity consumption, and the average yearly minimum load are in the increasing conditions; respectively presented as the value of $6.86 \%, 6.87 \%$ and $27.06 \%$ (see Equation 1 for the calculation of the average yearly values). These values are respectively $6.80 \%, 6.25 \%$ and $4.99 \%$ for the last ten years; $6.48 \%, 5.27 \%$ and $7.99 \%$ for the last five years; and also $8.13 \%, 7.34 \%$ and $1.81 \%$ for the last three years.

$$
\text { Average yearly value }=\frac{\sum_{i=1}^{n} \frac{\left(x_{i+1}-x_{i}\right)}{x_{i}}}{n}
$$

The main causes of this increase in the electricity demand may generally be given as the increase in the income growth, the increase in the population and/or even the decrease in the GINI coefficients/index. The GINI index, which is a measure of relative inequality, is calculated based on the Lorenz curve and the hypothetical absolute equality ( 0 of the GINI index: perfect equality; 100 
of the GINI index: perfect inequality) (Gastwirth, Modarres \& Bura, 2005; Worldbank, 2014). The Lorenz curve shows the unequal distribution of the wealth. Lorenz (1905) explained the wealth and the concentration of the wealth. These indicators in Turkey are tried to be presented to the readers on the Slides 3 to 8 (see ESF) by help of the historical data (1961-2011) of the gross domestic product (GDP), the population, the GINI index and the GDP per capita.

The amount of the electricity generation in Turkey has tried to be increased to supply necessary amount of the electricity in good quality for the compensation of the subjected demand, in other words the electricity consumption. One of the major shares in the supply side is covered by the hydropower plants. The historical data (the sum of the existing power plants' capacities and the capacities of the power plants under construction) for showing the progress of the installed capacity of the hydropower (supply) and the total installed capacity (supply) in Turkey is presented with the peak load (demand) and the minimum load (demand) in Turkey as shown on the Slides 9 to 11 (see ESF). There are two scenarios (high and low) for the Turkish Electricity System. The average values of these two scenarios are also presented. The average yearly projected installed capacity of the hydropower (MW) growth (the sum of the existing power plants capacities, the capacities of the power plants under construction, the capacities of the power plants granted by license) is 6\% for eight years (2013-2021), 10\% for five years (2013-2018), and 13\% for three years (2013-2016) (see Equation 1). The average yearly projected installed capacity of wind power (MW) growth is $3 \%$ for eight years (2013-2021). The average yearly projected installed capacity of nuclear power (MW) growth is $19 \%$ for eight years (2013-2021) from 0 MW to 3600 MW. The first nuclear plant in Turkey is planned to be in the operation in 2019 with an installed capacity of $1200 \mathrm{MW}$. The total yearly projected installed capacity growth is 4\% for eight years (2013-2021). These conditions, and predictions clearly indicate that the electricity generation power plant investments and more specifically the private hydropower plant investments in Turkey are attractive or in some daily investors speech or terminology sexy for the real sectors' investors or as sometimes titled as the real sectors investment players or as only players. Henceforth, new private hydropower plant investments have been searched, developed, investigated, selected and acquired resources by the private real sector investors or their dedicated staff by help of some analysis in Turkey. For instance, Statkraft (a European power company) (http://www.statkraft.com) preferred to invest into the private hydropower plants in Turkey and VERBUND (Austria's electricity company) (http://www.verbund.com) already took its market position in Turkey. Moreover, financial institutions (e.g. World Bank, Islamic Development Bank) have also been working on the analysis to find the right choice for them to appoint sufficient financial support.

One of the important problems in the real sectors for the private investors is the allocation and assignment of sufficiently appropriate resources such as money, time (manhour), and people (manpower) to the most satisfactory investments for themselves, which help to use the limited resources as efficiently as possible. The hydropower plant investments can't be accepted as a separate investment type diverged from this basic principle. Hence, the selection of the PHPIs 
amongst some alternative PHPIs based on the most appropriate methodology and principles is one of the critical problems for the private investors and also for the researchers, the managers, or the practitioners who consult the private investors or manage the real sector company. In today's world, in these very clanging and ever changing conditions, the investors and corporations employ some dedicated experts or sometimes hire some consultants to work on, to find out, to decide and to recommend the best private hydropower plant options for them. These kinds of investments are sort of the long term investments (50 years or more: some 80 years old plants in the world still operate) and kind of the real sector investments, so that to access or to invest to them is not easy and simple (observing almost 15 years procedural and so forth works until the start of operation in Turkey is not surprising) and also to exit or to withdraw or to set out is very difficult and troublesome (one decision for one generation of at least 50 years), so that the decision making procedure, application and afterwards the final decision by itself is very important for the parties that are involved to these investments and their related investigations. The chief executive officers, the managing directors, the managers of power and investment departments are some of the critical participants that carry the tremendous amount of responsibility on their shoulders.

The selection problem of the PHPIs amongst some of the options is one of the problem subgroup of the selection of an alternative or an option amongst some alternatives. This problem is a typical problem of the Multi Attribute Decision Making (MADM) or the Multiple Criteria Decision Making (MCDM) (please visit the International Society on Multiple Criteria Decision Making website for further info: http://www.mcdmsociety.org/). The MADM or MCDM problems are for sure very different from each other according to their sector, industry, alternatives or attributes size, scope and also specific problem. For instance, the investment selection amongst some alternatives in the financial markets and in the real sectors are very different from each other, but they both are the typical MADM or MCDM problems; or the investment selection problem in the agriculture sector and in the aviation sector can't be modeled in the same manner with ease, but they both are the typical MADM or MCDM problems. According to these basic clarifications, explanations and descriptions, the selection problem of the PHPIs have to be studied and investigated in detail as an important, unique and interesting subgroup by the researchers all over the world. The applications of different MADM methods or the combinations of these methods or the adaptations of the fuzzy theory and the grey theory should be implemented, executed, and completed by the researches in the different parts of the world to increase the number of the scientific studies and also the lessons learnt' or experiences' statements based on the true scientific principles for the next generations (humankind) to help them to take more appropriate, and more satisfactory PHPIs' decisions in all aspects.

The MADM problems can generally be solved by several methods such as the Analytic Hierarchy Process (AHP), the Decision EXpert (DEX), the Elimination and Choice Translating Reality (Elimination Et Choix Tradusiant la Realite) (ELECTRE), the MACBETH (Measuring Attractiveness by a Category-Based Evaluation Technique), the Preference Ranking Global Frequencies in Multicriterion Analysis (PRAGMA), the Preference Ranking Organization METHod 
for Enrichment Evaluations (PROMETHEE), the Technique for Order of Preference by Similarity to Ideal Solution (TOPSIS), the pros and cons, and the weighted product method (see Brans \& Vincke, 1985; Bridgman, 1922; Bohanec, Žnidaršič, Rajkovič, Bratko \& Zupan, 2013; Costa, De Corte \& Vansnick, 2012; Franklin, 1972; Hwang \& Yoon, 1981; Matarazzo, 1988; Roy, 1991; Saaty, 1990). Each of the MCDM method has its own pros and cons or familiarness and unfamiliarness at each problem for different decision makers.

The objective of this paper is to present to the consultants, the investors, the practitioners, and the researchers, how the most satisfactory PHPI option can be selected amongst some PHPI alternatives by help of the Decision EXpert method with ease and comparably short period of time with the limited available data and information in the early periods of the investment process. In addition to that, this study aims to develop a core model or a template, that may be preferred applying all over the world and ready to use for the selection of the PHPIs (new or also extended for in operation), including its own defined attributes in an organized manner by help of an application.

In the current study, a Virtual Private Investor (VPI) was designed for the evaluation of the real world data in the hydropower industry in Turkey for achieving the objectives of the study given in the previous paragraphs. The VPI was pretended to be only one person, who was both an expert (E) and a decision maker (DM). In the DEXi model, the EDM was also the decision analyst for this case. The expert decision maker (EDM) term was preferred to describe the VPI's technical characteristics. There was not any real investment aim of the VPI, hence the term virtual had been specifically chosen. The purpose of the VPI was to analyze the PHPIs and the hydropower market (electricity generation industry) in Turkey, and also to select the most appropriate PHPI according to the VPI's considerations, preferences and assumptions (characteristics of an IF WHAT IF conditional study in consideration). The options (in the DEXi terminology) (alternatives) were the real PHPIs in Turkey. There were 617 options in the current study. The VPI solved this PHPI selection problem in Turkey by mainly means of the search results clustering engine: Carrot $^{2}$, the hydropower plant clustering and the DEXi (DEX: Decision EXpert, DEXi: Decision EXpert for Education) (please be reminded that DEXi is not used for only education).

This paper has four sections. The related previous work is presented in the second section. The case, the methodology, the calculations and the results are explained in the third section. The conclusions and the scopes of the future research studies are presented in the fourth section. The models (four *.dxi files) are also presented for the readers in the electronic supplementary files (ESF). These models can be used as the template by the readers. In addition to these files, a presentation is also presented for the readers. 


\section{Literature Review}

The previous studies were tried to be found by the help of some scientific online database and journal websites. The literature review was performed according to the procedure (see the flowchart) presented on the Slides $12 \& 13$ in the ESF. The reviewed scientific online websites were the ACM Digital Library, the ASCE Online Research Library, the American Society of Mechanical Engineers, the Cambridge Journals Online, the Directory of Open Access Journals, the Emerald Insight, the International Journal of Industrial Engineering Theory, Applications and Practice, the Journal of Industrial Engineering and Management, the Science Direct, the Taylor \& Francis Online, the Wiley-Blackwell, and the World Scientific Publishing (Slide 14). Some generally used keywords related with the current subject were chosen based on their usage frequency in the scientific publications according to the author's experience for the reviewing process. These keywords were used for the searching purposes on these scientific online database websites with all fields' option selected until the $24^{\text {th }}$ of March in 2014 . The selected key words were cluster, DEX, DEXi, Decision EXpert, hydropower, investment, multi attribute, multi criteria, MADM, MCDM, plant, and private (Slides 15). These keywords were searched on the advanced search tools based on some search key terms. The summary of the literature review is presented (Slides 16 to 19). The searching process of these keywords showed that most of the found documents were not related with the subject. For instance, there were 7050 results found on the ACMDL, 71 results found on the ASCEOR, 20 results found on the ASME, 5037 results found on the CJO, 164 results found on the DOAJ, 23 results found on the EI, 0 results found on the IJIETAP, 0 results found on the JIEM, 1821 results found on the SD, 2755 results found on the TFJ, 40308 results found on the WB, and 387 results found on the WSP for the DEX keyword. Although there were quite large number of documents found according to the search results for the DEX keyword, only a few of them were related with the DEX (Decision EXpert) method. The main reason for this situation so called the improperness was the preference of the unlimited searching option on the scientific online database websites. When this option had selected on the search box of these websites, the algorithms automatically tried to find the word in any section and any place of the documents without case sensitivity. The documents, which were irrelevant with the subject of the current study, were eliminated in the further steps. After the investigation of these studies, it was observed that the most of the documents were irrelevant with the subject. The most relevant studies (larger point of view) found on the searched scientific online database websites were presented in this section.

One of the important subtopics of the current literature review was the clustering. One of the highest hits rate was also observed by the cluster keyword search amongst all keywords. The subjects of these documents were very separate and different from each other (from health to wireless communication). Several studies defined the clustering or the cluster analysis as: 
"Cluster analysis is a general logic process, formulated as a procedure by which groups together objects into groups based on their similarities and differences." (Palumbo, Lauro \& Greenacre, 2010; Trebuňa \& Halčinová, 2013.)

Several methods for clustering (e.g. simple linkage method, complete linkage method, median method) in the different scientific areas with the different advantages and disadvantages, were presented in the scientific publications (Alizadeh, Ghazanfari \& Fathian, 2008; Gabrys \& Bargiela, 2000; Liao, Chen \& Hsu, 2009; Po, Guh \& Yang, 2009; Strehl \& Ghosh, 2002; Wu \& Yang, 2002).

The other important subtopic was about the hydropower and at the same time the MCDM topics. This literature review was specifically very carefully performed for the hydropower plant investments and the MADM applications on them. There were some studies focused on the evaluation of the potential sites or the potential locations of the hydropower plants based on some criteria such as the electricity generation, the engineering and economics, the socio-economics, and the environment by a MCDM method such as the AHP or the total weighted scores (Rojanamon, Chaisomphob \& Bureekul, 2009; Supriyasilp, Pongput \& Boonyasirikul, 2009; Vucijak, Kupusovic, Midzic-Kurtagic \& Ceric, 2013) and also there were several studies focused on the evaluation of the energy systems (e.g. coal, gas, hydro, nuclear) based on some defined attributes such as the economics, the availability, the environmental impact, and the proliferation by help of several methods such as the equivalent attribute technique (EAT), the multi-attribute utility theory (MAUT) and the Choquet integral methodology (Abouelnaga, Metwally, Nagy \& Agamy, 2009; Kaya \& Kahraman, 2010; Loken, Botterud \& Holen, 2009). Surprisingly, it was realized that only very few number of researchers dealt with the selection problem of the hydropower plants and none of the researchers focused on solving the selection problem of the PHPIs.

The DEXi was preferred in this study, mainly because of the nature and the characteristics of the problem and the particular suitability of the method for the modeling and solving the current problem. The current problem could most easily be modeled by the judgment of the qualitative attributes (please be noted and reminded for the power and influence of words, phrases, terms and sentences). There were many attributes and many options of this problem. The problem (based on the real data) could be assumed as a kind of complex real-world problems. The data and information could not be accepted as fully and wholly accurate and existing. The DEXi models were developed for these kinds of situations. Moreover, the EDM didn't prefer to work with difficult and timely efforts of judgments on weighting of attributes in this early investment stage. The DEXi models were able to work without any attribute weights. The DEXi was developed for solving the MADM problems in 2000s (Bohanec, 2013). Its predecessors were respectively the DEX and the DECMAK (Bohanec et al., 2013). The first studies on the foundation of the DECMAK were started in the United Kingdom by Efstathiou and Rajkovic and continued in Slovenia by mainly Rajkovic and Bohanec (Efstathiou \& Rajkovic, 1979; Bohanec et al., 2013). The DECMAK was proposed in 1980's, the DEX (Decision EXpert) was developed as an expert system shell for solving the MCDM problems in 1987 and finally the DEXi was implemented in 2000's by Jereb, Bohanec, and Rajkovic 
(Bohanec, Bratko \& Rajkovič, 1983; Bohanec \& Rajkovic, 1990). The applications of the DEX and the DEXi were in a broad range such as agriculture, banking, ecology, health-care, project evaluation, housing, information technology, sports, and tourism (Bohanec, 2013; Bohanec, Messean, Scatasta, Angevin, Griffiths, Krogh et al., 2008; Bohanec, Messéan, Scatasta, Džeroski \& Žnidaršič, 2005; Bohanec \& Rajkovic, 1999; Bohanec et al., 2013; Kontic, 2013; Sadok, Angevin, Bergez, Bockstaller, Colomb, Guichard et al., 2009; Taskova, Stojanova, Bohanec \& Džeroski, 2007). The DEX (runs on the DOS) was able to deal with probabilistic and fuzzy distribution of values (Bohanec, 2013). The DEXi, which is nowadays seemed as the specific software of the DEX method, is more powerful than the DEX, which is accepted as the method only, in several aspects, such as in the analysis of options, having powerful visualizations and graphics, and capable of using weights (e-mail correspondence with Professor Dr. Marko Bohanec). In this study, the detailed information for the DEX and the DEXi were also gathered by additionally reviewing of the previous studies, applications and summary of the method on the official websites (see Arh \& Blažič, 2007; Bohanec \& Rajkovič, 1990) (http://kt.ijs.si/MarkoBohanec/dex.html) (http://kt.ijs.si/MarkoBohanec/dexi.html).

The literature review showed that this paper would most probably be one of the first studies according to not only the aim, but also the application of the DEXi in the hydropower industry in this scientific research field.

\section{Model Development, Execution and Results}

The basic model was developed based on the procedure presented in Figure 1.

This study covered all of the private hydropower plant investments (PHPIs) in any sizes (installed capacities) in Turkey. The selection of the PHPIs couldn't be done in an appropriate way to get the useful results without taking into account the size of the hydropower plant. For instance, the comparison of a $100 \mathrm{~kW}$ installed capacity hydropower plant and a $100 \mathrm{MW}$ installed capacity hydropower plant couldn't be seen as meaningful on the private investors point of view. In addition to that the judgments of the attributes on these kinds of comparisons so that the following decisions couldn't be certainly accepted as performed on the correct and distinct human perception and comprehension principles. Henceforth the clustering had to be completed before going into the detailed evaluations of the alternatives. The clustering in the current model (very simple clustering) was only based on the installed capacity. The PHPI options could be grouped based on their similarities according to their properties. Although there had not been taken any consensus on the classification of the installed capacities of the hydropower plants yet, the installed power of the hydropower plants could still be taken as one of the basic similarity properties. On the other hand, the general consensus of the classification of the installed power of the hydropower plants was almost achieved according to the name/title of the installed power of the plants as large, medium, small, mini, micro and pico 
hydropower plants. Some academics worked on the classification of hydropower plants by the installed power or capacity (P) (see Anderson, Doig, Khennas \& Rees, 1999; Castaldi, Chastain, Windram \& Ziatyk, 2003; Mishra, Singal \& Khatod, 2012; Paish, 2002; Voros, Kiranoudis \& Maroulis, 1999). The simple clustering algorithm in this model was built up according to the Algorithm 1 on Figure 1 ( 0 to 1,1 to 10,10 to 100 , and 100 to 1.000 in MW). There was not any option, that had the installed power less than $0.5 \mathrm{MW}$, in the options' data set. There were 8 options in the mini private hydropower plants cluster, 354 options in the small private hydropower plants cluster, 228 options in the medium private hydropower plants cluster, and 27 options in the large private hydropower plants cluster.

The attributes (the basic attributes: see Chapter 2.7 Attribute in Bohanec, 2013) were identified and selected according to some selected key terms based on some previous studies (Chou, 2007; Hossain \& Das, 2010; Lin \& Juan, 2009; Mokhtarian \& Hadi-Vencheh, 2012; Saracoglu, 2013; Weaver, 2012) and by the expert opinion of the EDM. The unstructured selected attributes, which were described by the key terms were total energy generation, river basin, community attitude, transportation, security conditions, terrorism conditions, protected areas, substation conditions, business climate, climate change, ambient temperature change predictions, precipitation change predictions, electricity demand, transmission system network, distribution lines network, credit availability, cost, labor, availability of workforce, availability of skilled labor, natural disasters/hazards, earthquakes and zones, free travel, geopolitical uncertainty, war conditions, social chaos, air transportation, railway transportation, road transportation, inland waterway transportation, oceansea transportation, technological infrastructure, and scientific infrastructure (Slide 20).

As generally presented in the scientific studies, the attributes had to be relevant, grouped only in one class, effective and operative. The abstract concepts, expressions and meanings of these selected key terms and phrases (the perception of the EDM on the linguistic terms) for the EDM, which had to describe and explain the attributes very well, were analyzed by the EDM with adopting and using the search results clustering engine. The Carrot ${ }^{2}$ application (the mining product) (http://project.carrot2.org/) was preferred for gathering information about the terms and phrases of the attributes and analyzing the terms related with the attributes (complete understanding) and also for the clustering of the terms and phrases. The usage of the Carrot $^{2}$ application helped for also structuring the attributes. The Carrot ${ }^{2}$ had three clustering algorithms (Lingo, STC: Suffix Tree Clustering, and K-means) while this study was conducted (Slides 21 to 44). These three clustering algorithms were used effectively during the study. After this step, some of the key words were eliminated and some new ones were added by the EDM and the unstructured selected attributes were decided as total energy generation, investment cost, river basin, precipitation change, ambient temperature change, natural disasters/hazards, community attitude, protected areas, technological infrastructure, scientific infrastructure, electricity demand status/situation, electricity demand forecast/prediction, substation status/condition, distribution system status/condition, transmission system status/condition, war situation, terrorism situation, 
geopolitical uncertainty situation, security situation, free travel situation, social chaos situation, road transportation, railroad transportation, air transportation, waterborne transportation, business climate status/situation, and business climate prediction. These basic attributes (enough in number and in detail) would give the opportunity to investigate and evaluate the options in the early investment stages. In the other investment stages of the PHPIs, some additional basic attributes could be added to this model. The data and information of these added attributes could only be gathered from the documents, the activities' observations, the calculations and the reports such as the pre-feasibility, the feasibility studies, the technical specifications, the contracts, the construction works, or the electromechanical works in the later investment stages. The complete understanding of the attributes and options was very important for the evaluations.

The evaluations on these attributes could not be performed directly in this structure, because having from two to four descendants for each aggregate node was strongly recommended in the DEXi models (e-mail correspondence with Professor Dr. Marko Bohanec and Bohanec, 2013). The attributes were taken as the basic attributes and new aggregate attributes were defined by the bottom-up structuring. The structure and tree view of the current model was drawn by DEXiTree Version 0.91 (see Figure 2 and Slide $45 \& 46$ ).

Some of the basic and aggregate attributes according to the knowledge of the EDM on the linguistic terms were tried to be explained as simple as possible in the shortest form. This study was performed based on the realistic daily life data and information. The knowledge was gathered from several sources. The data and information richness on each option according to each attribute was very critical during the evaluation of the EDM. As a consequence, not only the modeling of the MADM problem, but also the knowledge management during solving the problem was a research issue by itself. The knowledge management principles and the data and information management principles had to be kept in mind and applied during these kinds of research studies for getting relevant and considerable findings.

Total energy generation (TEG): The estimated total electricity generation data of the PHPI options were taken from the official records in the current study (data set from GDSHW, 2013; EMRA, 2013; TEIAS, 2013) (see Table 1 for estimated total electricity generation (kWh) in scale). 


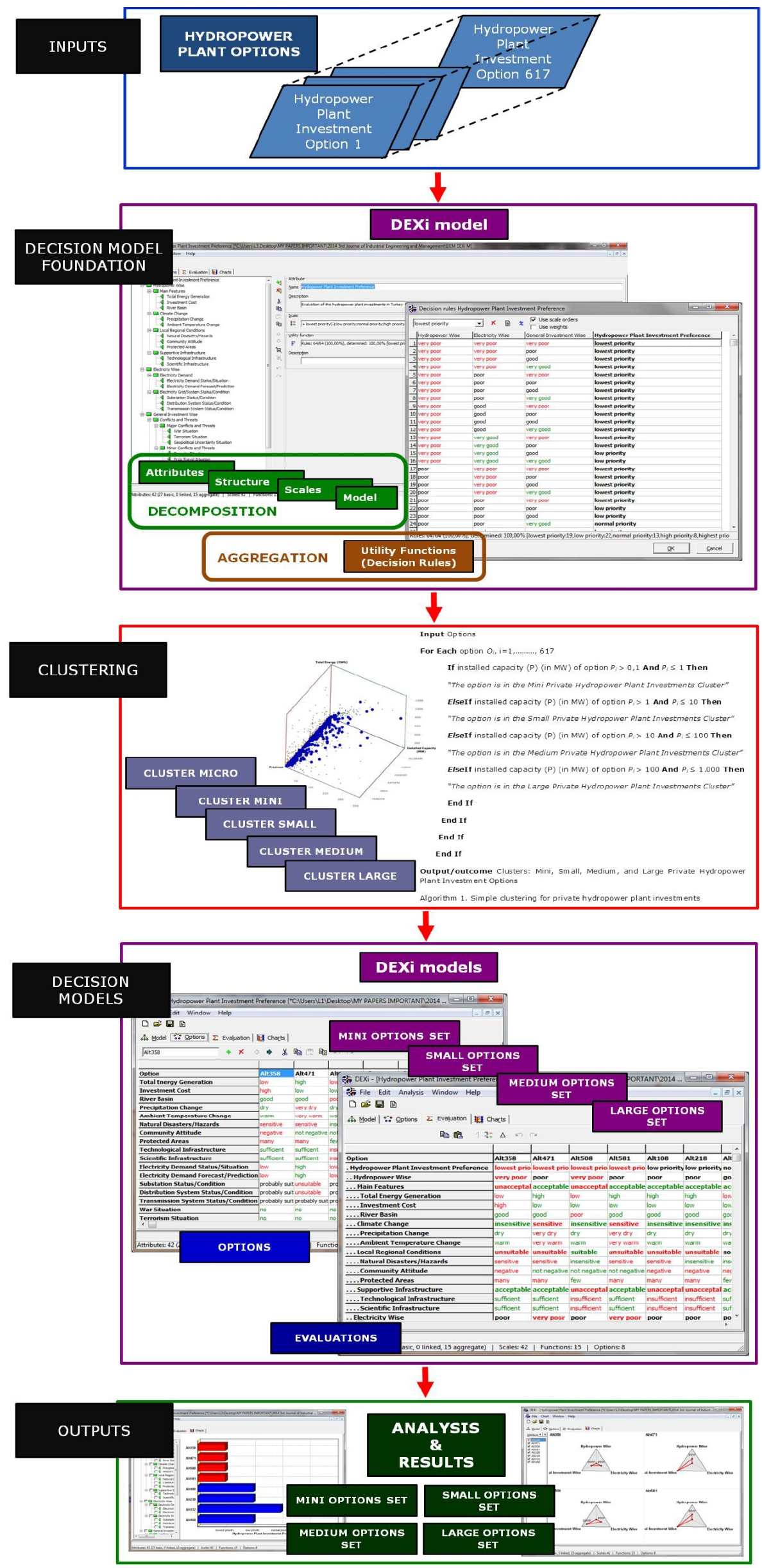

Figure 1. The structure of the framework of the current study 
Investment cost (IC): The estimated investment costs of the PHPI options in the current study were calculated based on the installed power of the hydropower plants and the historical data or figure of the total installed cost presented by the IRENA (International Renewable Energy Agency). The IRENA had presented the total installed cost data in different ranges for the small and large hydropower plant projects in the European Union, the United States, Africa, Eastern Europe and Central Asia, Other Asia, China, India and Latin America. In the current study, the cost data of the Eastern Europe and Central Asia group was taken into consideration. The costs for small hydropower plant projects in the IRENA data set were ranged between approximately (approx.) 1000 USD/kW and approx. 2000 USD/kW in 2011 and the costs for large hydropower plant projects in the IRENA data set were ranged between approx. 1000 USD/kW and approx. 4000 USD/kW in 2011 (IRENA, 2014) (see Table 1 for investment cost (USD) in scale).

River basin (RB): The main river basin of the PHPI option was evaluated by the EDM (expert opinion). The river basin term and the geographical regions (Aegean, Black Sea, Central Anatolia, Eastern Anatolia, Marmara, Mediterranean, and Southeastern Anatolia) of Turkey should not be confused with each other (see Table 1 in scale).

Climate Change (CC): The evaluations of these basic attributes were done or performed based on the IPCC (Intergovernmental Panel On Climate Change) (https://www.ipcc.ch) climate change studies. The temperature and precipitation projections of the future climate change for the near term 2016-2035 and for the mid-term 2046-2065 were taken from the Climate Change 2013: The Physical Science Basis report (IPCC, 2014) (see Table 1 in scale).

Local Regional Conditions (LRC): The natural disasters/hazards, the community attitude and the protected areas were evaluated by the EDM (expert opinion) based on the data and information from several sources such as (http://www.deprem.gov.tr/, http://www.eba.gov.tr/, http://www.mgm.gov.tr/, http://www.milliparklar.gov.tr/, http://www.kulturvarliklari.org/, http://www.ogm.gov.tr/). The community attitude was observed as one of the critical issues in the private hydropower plant investment processes in Turkey. In some cases, these legal court cases shifted the construction schedules several years, and in some cases the hydropower plant investments (the licenses) were cancelled in Turkey. The protected areas were evaluated based on the data and information of the natural parks, the ecological values (sites), the cultural values (sites), and the regional values (sites). The number and the area of these protected areas affected and influenced the PHPI processes, added very long durations to the time consuming procedural works and the legal permissions (see Table 1 in scale). 


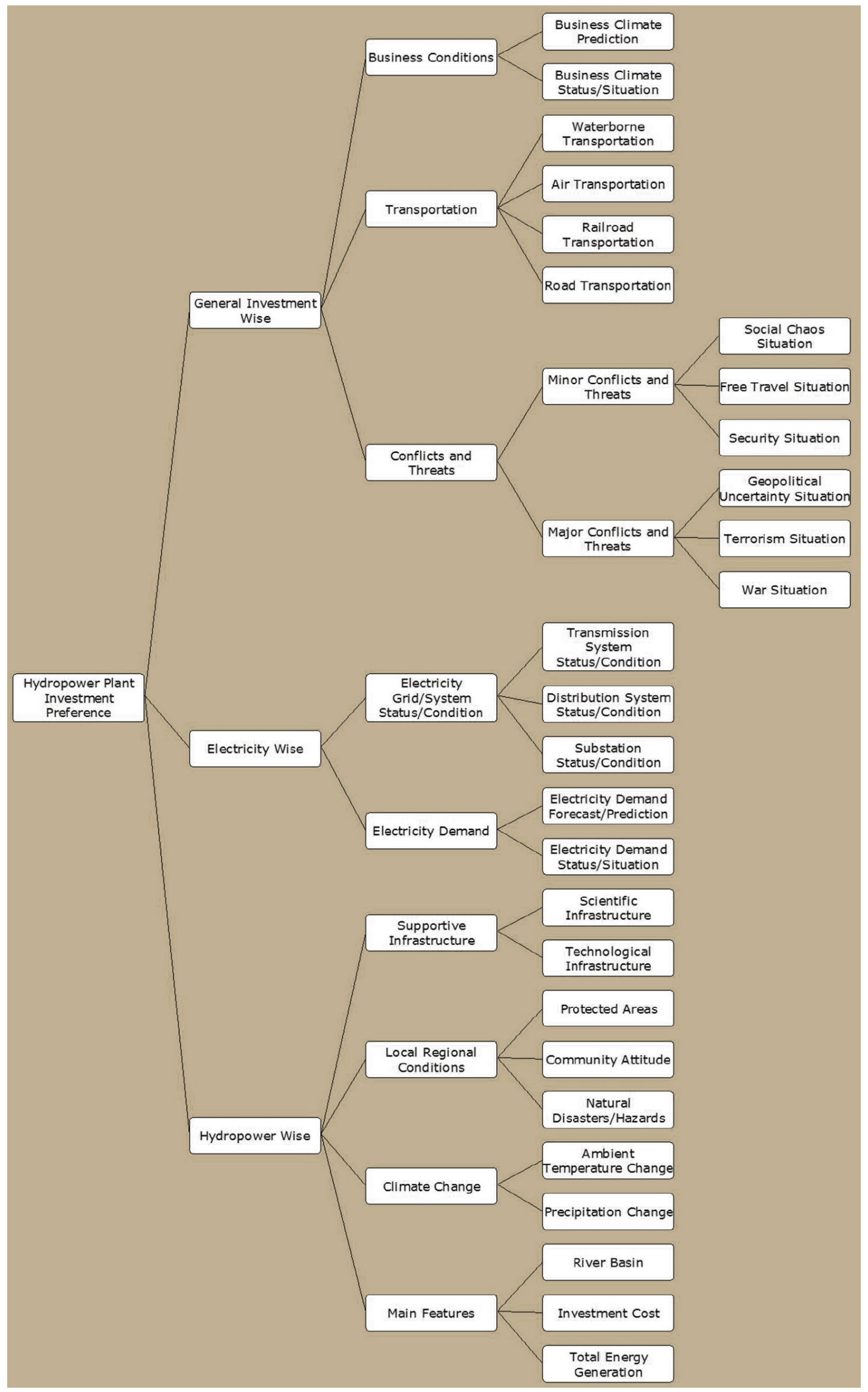

Figure 2. The tree structure view of the current model (DEXiTree) 
Supportive Infrastructure (SI): The technological and scientific infrastructures were evaluated by the EDM (expert opinion) based on the information from several sources. The observations in several hydropower plants construction periods showed that the test facilities, the certification offices and other supportive organizational structures were very important for the total duration and the cost of the construction and the acceptance period of the hydropower plants (see Table 1 in scale).

Electricity Demand (ED): The amount of the current electricity demand and the electricity demand predictions were evaluated by the EDM based on the information from several sources. The general consensus were achieved in the electricity sector that the distance or the proximity of the demand centers and the supply centers (generation plants) had to be taken into account for the modeling of the whole electrification system (please be to know that the amounts, the sizes or the capacities are very important in this consideration) (see Table 1 in scale).

Electricity Grid/System Status/Condition (EGSSC): The substations status, the distribution systems conditions and the transmission system conditions were evaluated by the EDM based on the information from several sources. The observations were made on the constraints of the national substation network (see Table 1 in scale).

Major Conflicts and Threats (MCT): The war, the terrorism and the geopolitical uncertainty situations were evaluated by the EDM based on the information from several sources such as (http://www.un.org/en/terrorism/index.shtml), (http://www.nato.int/cps/en/natolive/76706.htm) visited during this study (2013-2014). The major conflicts could not be solved with ease in the short to mid terms. The effects would continue and stand in the long term (please keep in mind fifty to hundred years or even several hundred years and also affects on the related strategic plans). The public resources were spent ineffectively and inefficiently in these regions (for instance: very high spending or expenditure for military forces to weapons and staff (note that: military forces are some sort of the non-productive units of the governments and the communities) instead of the agriculture such as the organic farms, the health such as the hospitals, the energy such as the power plants). The psychological effects of the major conflicts and threats were also very devastating and passed or transferred from one generation to the following one. The general consensus amongst the real sector investors were already achieved that the investments were more satisfactory and more manageable in the safe, secure, peaceful and non-turbulent regions (perfect condition for real sector investments: no major conflicts and threats, all resources attended for the research \& development, the production, and manufacturing activities in the agriculture, the education, the energy, the health, and the transportation) (see Table 1 in scale).

Minor Conflicts and Threats (MICT): The perceived security, the free travel situation, and the social chaos situation were evaluated by the EDM based on the information from several sources such as (http://www.unodc.org/unodc/en/drug-prevention-and-treatment/), 
(http://www.unodc.org/unodc/en/human-trafficking/) visited during this study (2013-2014). The evaluations were performed in the areas such as the human security, the public security, and the infrastructure security. The official records such as the theft and burglary data and information were gathered and taken into consideration during the evaluation of this attribute. The public resources were spent ineffectively and inefficiently in these regions (for instance: very high spending or expenditure for police and security forces (note: police and security forces are some sort of the non-productive units of the governments and the communities) for rifles, guns and staff instead of the agriculture such as the organic farms, the health such as the hospitals, the energy such as the power plants) like in the major conflicts and threats attribute, however the amount was generally small when compared to the major conflicts and threats (perfect condition for real sector investments: no minor conflicts and threats, all resources attended for the research \& development, the production and manufacturing activities in the agriculture, the education, the energy, the health, and the transportation) (see Table 1 in scale).

Transportation $(T)$ : The availability, the ability, the flexibility, the quality, and the general conditions of the road transportation, the railroad transportation, the air transportation and the waterborne transportation were evaluated by the EDM based on the information from several sources such as (http://www.dhmi.gov.tr/, http://www.tcdd.gov.tr, http://www.kgm.gov.tr) visited during this study (2013-2014) (see Table 1 in scale).

Business Conditions ( $\mathrm{BC})$ : The business climate status and predictions were evaluated by the EDM based on the information from several sources such as some web pages (www.tuik.gov.tr) visited during this study (2013-2014) (see Table 1 in scale).

The attributes, the scales of the attributes and the structure of the model were same for four clusters, mini, small, medium and large private hydropower plant investment options as presented in Table 1. The options and the evaluations for options were different for these clusters, so that four different DEXi files based on the template or foundation/base model were created for four clusters.

The human's cognitive capability and limitations such as the human multitasking and the working memory issues were the key modeling or model design pillars of the current study. For instance, the increasing scales were preferred specifically and intentionally according for the usefulness of the human cognition limitations or the comprehensibility limitations of the humankind; or the current model (the basic and aggregate attributes and their structure) was designed according to the human cognitive capacity for processing information, or according to the short term memory capacity such as the magical number $7,7 \pm 2$ rule (see Miller, 1956; Shiffrin \& Nosofsky, 1994; Kintsh \& Cacioppo, 1994; Schweickert \& Boruff, 1986). Moreover, the scale size of the basic attributes was selected in the least number of distinguishable values 
and increased gradually on the root of the current model on each aggregate attribute until the target attribute.

The target attribute was scaled as the lowest priority, the low priority, the normal priority, the high priority, and the highest priority. These set of words for the discrete scales were selected to express and describe the target attribute preferences or values (hydropower plant investment preference) very well for the VPI and the readers.

The private hydropower plant investment options were entered one by one for each cluster (mini, small, medium and large) into the DEXi model (one DEXi file for each cluster). The input values of the options (the evaluations) were selected from the defined scales for each cluster by its own DEXi file as presented in Slides 47 to 58 . The analysis (each one) was performed for each cluster from the evaluation, the analysis and the charts tabs of the DEXi software.

In the mini PHPI options cluster, the most preferred mini PHPI option was the Alt332 with a preference of the normal priority. The mini PHPI options the Alt108, the Alt218 and the Alt168 had the preference degree of the low priority. Moreover, the Alt358, the Alt471, the Alt508, and the Alt 581 got the lowest priority preference degree. Henceforth, the Virtual Private Investor (VPI) would prefer to invest in the Alt332 in the mini PHPI options cluster under these assumptions, conditions and evaluations for VPI's satisfaction. The results of the analysis of this cluster were presented in Slides 59 to 65 . The graphical display of the results of this study for the mini PHPI options cluster was drawn according to the DEXi model as presented in Figure 3. The triangle shapes of the graphs (the pyramids) showed the evaluations of the results of the hydropower wise main aggregate attribute, the electricity wise main aggregate attribute, and the general investment wise main aggregate attribute of the DEXi model for each option respectively. The overall evaluation results for each option were presented with a bar graph in the center of the figure. 


\begin{tabular}{|c|c|c|c|c|c|}
\hline \multicolumn{5}{|c|}{ Attribute } & \multirow{2}{*}{$\begin{array}{l}\text { Scale } \\
\text { +lowest priority }(-) \text {; low priority; normal priority; high } \\
\text { priority; highest priority }(+)\end{array}$} \\
\hline HPIP & & & & & \\
\hline & HW & & & & +very poor(-); poor; good; very good(+) \\
\hline & & MF & & & +unacceptable(-); acceptable(+) \\
\hline & & & TEG & & $+\operatorname{low}(-) ; \operatorname{high}(+)$ \\
\hline & & & IC & & + high(-); low $(+)$ \\
\hline & & & RB & & $+\operatorname{poor}(-) ; \operatorname{good}(+)$ \\
\hline & & $\mathrm{CC}$ & & & + sensitive(-); somewhat sensitive; insensitive $(+)$ \\
\hline & & & PC & & + very $\operatorname{dry}(-) ; \operatorname{dry}(+)$ \\
\hline & & & ATC & & +very warm(-); warm(+) \\
\hline & & LRC & & & +unsuitable(-);somewhat suitable; suitable $(+)$ \\
\hline & & & $\mathrm{NDH}$ & & + sensitive $(-)$; insensitive $(+)$ \\
\hline & & & CA & & + negative(-); not negative $(+)$ \\
\hline & & & $\mathrm{PA}$ & & + many $(-) ;$ few $(+)$ \\
\hline & & SI & & & $\begin{array}{l}\text { +unacceptable(-);neither acceptable nor acceptable; } \\
\text { acceptable }(+)\end{array}$ \\
\hline & & & TI & & + insufficient(-);sufficient $(+)$ \\
\hline & & & $\mathrm{SCI}$ & & + insufficient(-);sufficient(+) \\
\hline & EW & & & & +very poor(-); poor; good; very good(+) \\
\hline & & ED & & & +low(-);medium; high $(+)$ \\
\hline & & & EDSS & & $+\operatorname{low}(-) ; \operatorname{high}(+)$ \\
\hline & & & EDFP & & $+\operatorname{low}(-) ; \operatorname{high}(+)$ \\
\hline & & EGSSC & & & $\begin{array}{l}\text { +unsuitable(-); somewhat suitable; quite suitable; } \\
\text { suitable }(+)\end{array}$ \\
\hline & & & SSC & & +unsuitable(-);probably suitable; suitable $(+)$ \\
\hline & & & DSSC & & +unsuitable(-);probably suitable; suitable (+) \\
\hline & & & TSSC & & +unsuitable(-);probably suitable; suitable (+) \\
\hline & GIW & & & & +very poor(-); poor; good; very good(+) \\
\hline & & $\mathrm{CT}$ & & & +risky(-); somewhat risky; quite risky; not risky $(+)$ \\
\hline & & & MCT & & +risky(-); quite risky; not risky $(+)$ \\
\hline & & & & WS & + yes $(-) ;$ no(+) \\
\hline & & & & TS & + yes(-); no(+) \\
\hline & & & & GUS & + high(-);low(+) \\
\hline & & & MICT & & +risky(-); quite risky; not risky(+) \\
\hline & & & & SS & + poor $(-) ; \operatorname{good}(+)$ \\
\hline & & & & FTS & $+\operatorname{poor}(-) ; \operatorname{good}(+)$ \\
\hline & & & & SCS & + yes(-); no(+) \\
\hline & & $T$ & & & + poor(-); fair; good(+) \\
\hline & & & RT & & $+\operatorname{poor}(-) ; \operatorname{good}(+)$ \\
\hline & & & RRT & & + poor(-); $\operatorname{good}(+)$ \\
\hline & & & AT & & + poor(-); $\operatorname{good}(+)$ \\
\hline & & & WT & & $+\operatorname{poor}(-) ; \operatorname{good}(+)$ \\
\hline & & $\mathrm{BC}$ & & & + poor(-); fair; good(+) \\
\hline & & & BCSS & & + poor $(-) ; \operatorname{good}(+)$ \\
\hline & & & $\mathrm{BCP}$ & & + poor(-); $\operatorname{good}(+)$ \\
\hline
\end{tabular}

Table 1. The structure and the scales of the model. Abbreviations: paragraphs above 


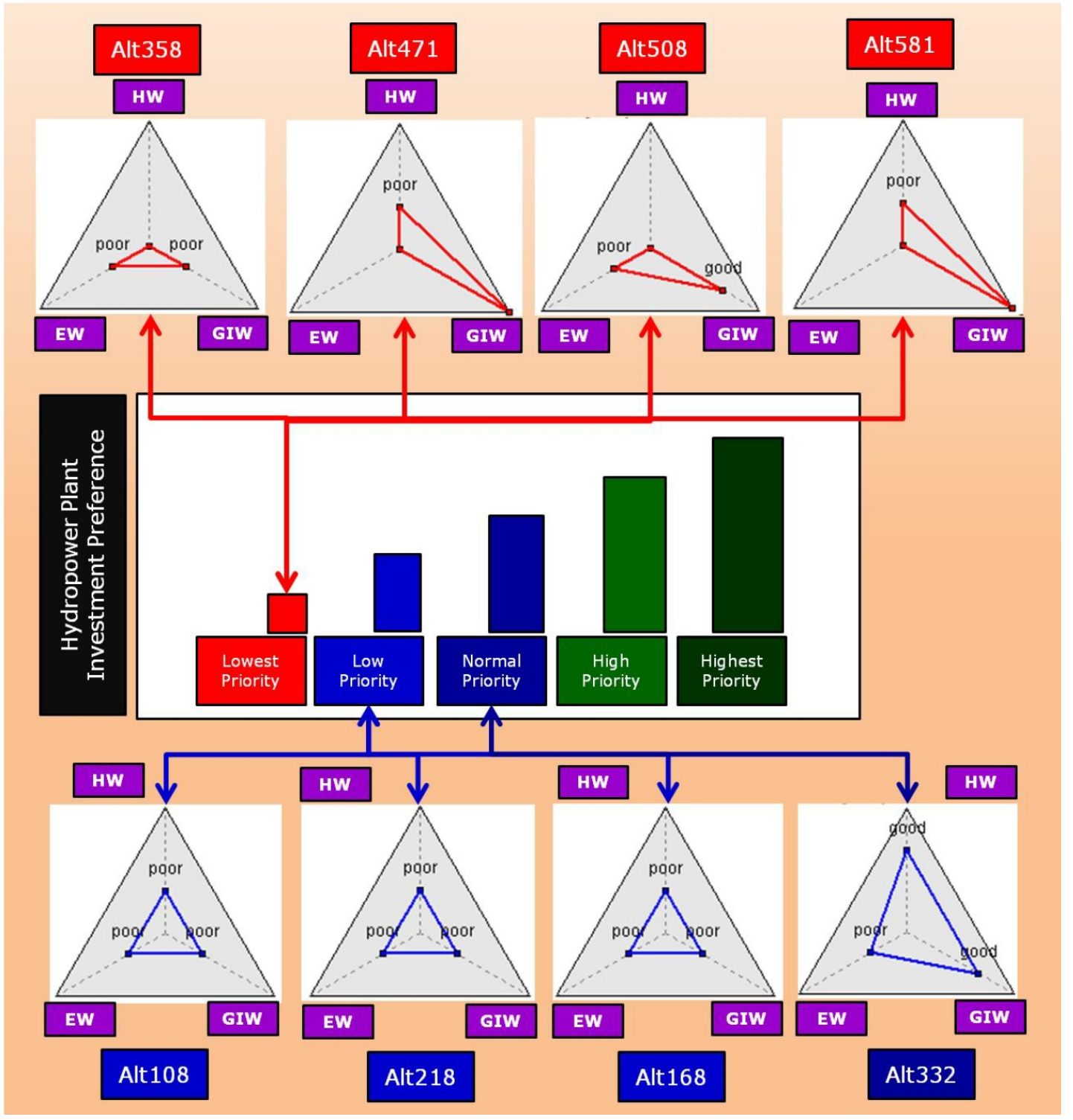

Figure 3. The graphical display of the evaluation of the DEXi model for the mini private hydropower plant investment options cluster

In the small PHPI options cluster, the most preferred small private hydropower plant investment options were the Alt362, the Alt238, the Alt418, and the Alt251, with a preference of the high priority. These four small PHPI options were the most satisfactory and appropriate options amongst all of the small PHPI options for the VPI. In addition, the Alt598, the Alt213, the Alt386, the Alt160, the Alt139, the Alt100, the Alt567, the Alt575, the Alt413, the Alt530, the Alt406, the Alt165, the Alt305, the Alt199, the Alt300, the Alt349, the Alt374, the Alt438, the Alt422, the Alt436, and the Alt532 had the preference degree of the normal priority. 21 small PHPI options were ranked in the normal priority PHPI preference. 4 small PHPI options with the high priority amongst the 354 small PHPI options in the small PHPI cluster would be paid attention by the VPI under these assumptions, conditions and evaluations for VPI's satisfaction. The results were presented in Slides 66 to 88 . 
In the medium PHPI options cluster, the most preferred medium PHPI options were the Alt095, and the Alt035, with a preference of the high priority. These two medium private hydropower plant investments options were the most satisfactory and appropriate options amongst the entire medium PHPI options for the VPI. In addition, the Alt196, the Alt395, the Alt097, the Alt092, the Alt130, and the Alt451 had the preference degree of the normal priority. 6 medium PHPI options were ranked in the normal PHPI preference. 2 medium PHPI options with the high priority amongst the 228 small PHPI options in the medium PHPI cluster would be paid attention by the VPI under these assumptions, conditions and evaluations for VPI's satisfaction. The results were presented in Slides 89 to 106 .

In the large PHPI options cluster, the most preferred large PHPI option was the Alt211 with a preference of the normal priority. The large PHPI options the Alt003, the Alt009, the Alt579, the Alt601, the Alt204, the Alt387, the Alt123, the Alt120, and the Alt187 had the preference degree of the low priority. The others got the lowest priority preference degree. Henceforth, the VPI would prefer to invest in the Alt211 in the large PHPI options cluster under these assumptions, conditions and evaluations for VPI's satisfaction. The results were presented in Slides 107 to 116.

The overall results of the analysis were presented in Figure 4. As seen on the figure, there were not any options with the highest priority of the hydropower plant investment preference degree. The overall threshold degree was decided as the normal priority (Slide 117). The best options in this 617 private hydropower plant investment options for the Virtual Private Investor according the VPI's preferences and evaluations on the current conditions and assumptions were presented in Figure 5 (Slide 118).

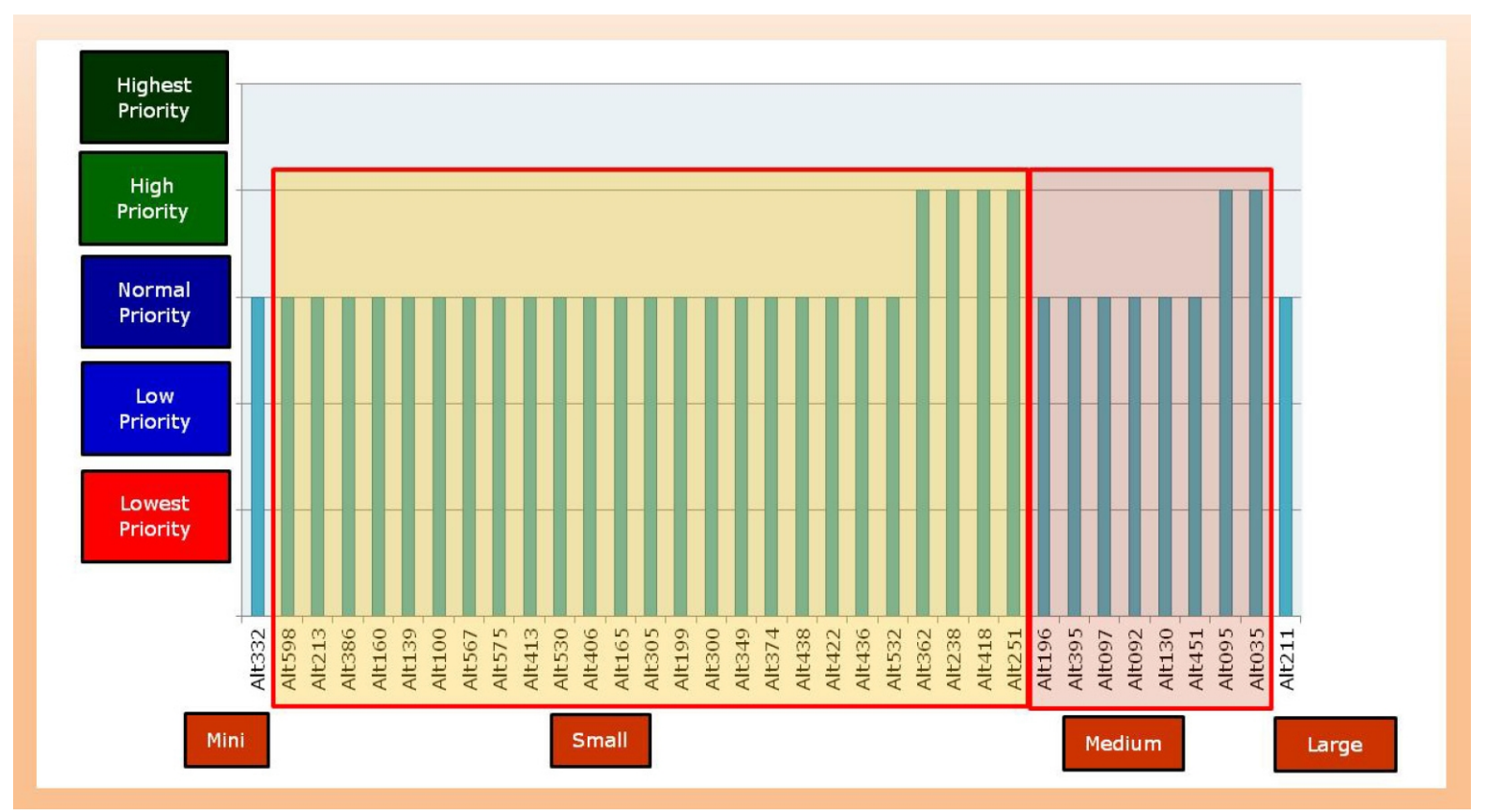

Figure 4 . The overall results of the analysis 


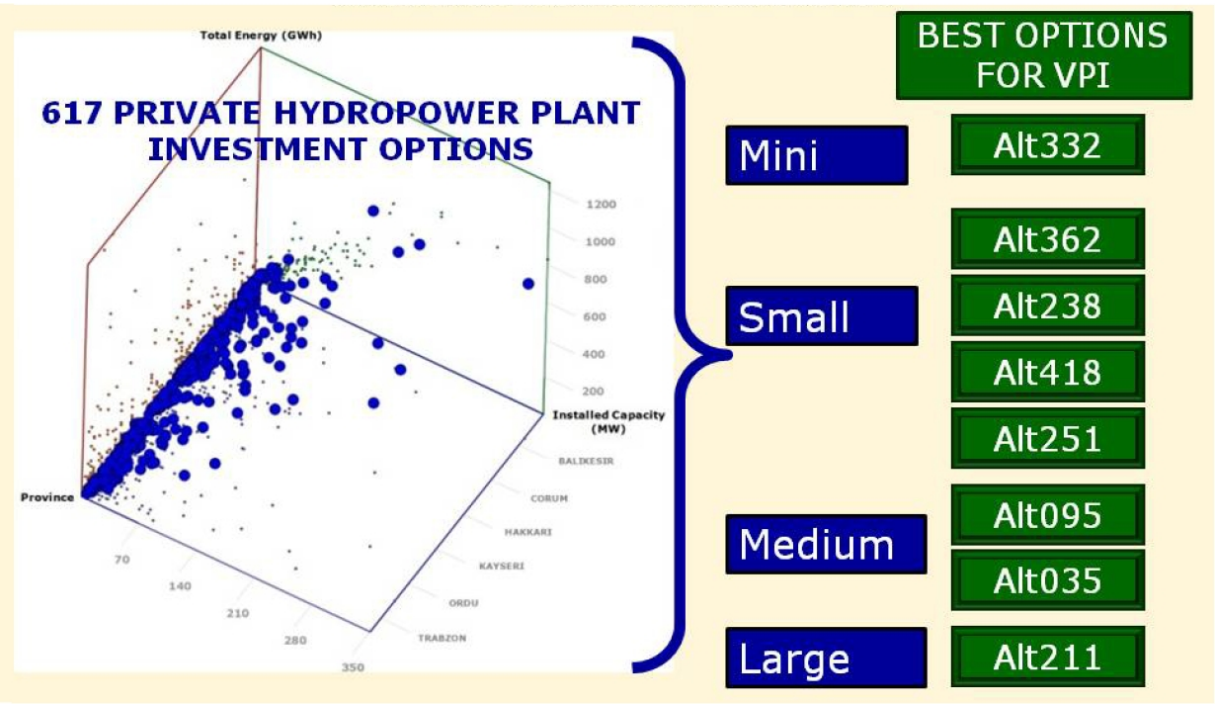

Figure 5. The best options in the PHPI data set for the VPI

In this study, the VPI preferred to analyze the best PHPI options in more detail by conducting the plus-minus- 1 analysis and the selective explanation tool. The strong points and the weak points of the best PHPI options were presented in Slide 119 to 128.

The Alt095 in the medium PHPI cluster had some strong points and at the same time some weak points. Some of the strong points of the Alt095 were the main feature, the climate change, and the supportive infrastructure, on the other side some of the weak points of this PHPI options were the river basin, the natural disasters/hazards, and the railroad transportation. The main features attribute of the Alt095 was in the strong points side, despite the fact that the river basin attribute was in the weak points side. This situation could be confusing to the readers; however the main features attribute was consisted of three basic attributes as the total energy generation, the investment cost and the river basin. The utility function, which was defined and ruled by the VPI, played the key role in this evaluation and the main features attribute was found as the strong points of the Alt095. Similarly, the plus-minus-1 analysis for the Alt211 was presented in Slide 119 for only the hydropower plant investment preference attribute. In this analysis, whenever it was possible to change the basic attribute value down or up one degree (for instance: possibility of the river basin from good to poor), the basic attribute value was changed (for instance: the river basin from good to poor) and the selected attribute was analyzed (for instance: the preference degree pushed to the lowest priority). According to this analysis, the Alt211 could not be in any better preference degrees, however it could be in the low priority degree or in the lowest priority degree. In addition to that, the total energy generation, the river basin, the substation status/condition and the transmission system status/condition attributes could affect the hydropower plant investment preference target attribute in the minus-1 simulation and moved the target attribute to the lowest priority. The plus-minus- 1 analysis of the best options of the medium PHPI options clusters was presented like a comparison chart on one 
slide for the ease of understanding in Slide 128. All of the other issues were presented from Slide 129 to 140 .

After these analyses, the VPI had the opportunity to manage the VPI's investment portfolio in one of the real sectors, the hydropower plant industry. The VPI could prefer to invest in the small or the medium or the large PHPI clusters. The VPI could also prefer to invest two or more clusters at the same time or even the VPI could prefer to have some shares from different PHPI options from different PHPI clusters in VPI's real sector investment portfolio at the same time. These analyses could be performed considering some other issues.

In real life applications, the private investors or the executives of the private investors can use these findings and discuss the investment strategies at the board meetings. The real investment financial power, the business capability, or the investment strategy plays the key roles on the investment strategies and the real sector investment portfolio. All of these issues are related with the preferences of the private investors and their executive.

The readers can have these DEXi files on the official webpage of the Journal of Industrial Engineering and Management (IJEM DEXi Model Cluster Mini.*DEXi, IJEM DEXi Model Cluster Small.*DEXi, IJEM DEXi Model Cluster Medium.*DEXi, and IJEM DEXi Model Cluster Large.*DEXi). These files can directly or with some changes/modifications be used as a template for these kinds of studies with ease.

\section{Conclusions and Future Work}

One of the important problems of the private hydropower plant investors and their executives in the world is the selection of the most appropriate and satisfactory private hydropower plant investments for themselves. The decision on this area affects not only the life of the private investors and the managerial team of the private investors but also their children' or offspring's' or descendants' lives and also the regions that are on the investment table pallet for considering development of the region. During the investment stages of the real sectors, especially at the very early stages, the private investors and their executives are very stressed, overwhelmed, and totally exhausted, unlike the public investment cases or the short term investment cases. The reasons of these conditions and the pressure over the private investors and their executives are very obvious, the gain or the loose. On one hand, there are only two final results of this game, on the other hand, there are remarkable numbers of the variables and the parameters that can be modeled and studied, and there are indefinite numbers of the variables and the parameters that can't be defined, modeled and analyzed. The data and information richness and poorness is also one of the important aspects of the real sector private investments. Being a local private investor, or a domestic private investor or a foreign private investor is also very interesting issue for the private investors. In addition to that, investing by a partner such as in an international joint venture case or a domestic joint 
venture case is also a very interesting issue. In short, being a private investor in real sectors and their executives is very difficult so that the researchers should develop tools for them to support them as much as they can to make their decisions in a scientific manner.

There are several methods for solutions of the MADM or MCDM problems. The DEX (Decision EXpert) or the DEXi (Decision EXpert for Education) helps very much for the solution of these kinds of problems.

In this study, the solution of the private hydropower plant investment selection problem in Turkey was successfully solved by help of the DEXi software and the DEXiTree software. The clustering (simple clustering algorithm) was a necessity or a must in this case, because of the difference of the characteristics of the hydropower plants. The clustering algorithm was very simple. The attributes like the investment incentives wasn't taken into account in the current model, because there were not any investment incentives in the hydropower industry in Turkey. The search results clustering engine (Carrot ${ }^{2}$ ) was very helpful not only for the comprehension of the attributes but also the clustering of these attributes. It was showed that the current model could be recommended to the executive managers, the investors and the consultants for their use and adaptation to their studies.

The major limitation of this study was the number of the EDM. These kinds of studies can be more fruitful when the number of the EDMs increased with the capability of performing evaluations on each major attribute. In addition to that, the questionnaire surveys, in depth interviews, and the telephone interviews should be conducted.

This study can be taken as a framework for the selection of the private hydropower plant investments in Turkey and it can be re-performed after gathering more detailed, more accurate and sufficient data and information on each option for each attribute. Moreover, this study and these kinds of studies should also be conducted as for the worldwide type of investigations within an international board and a group of experts and decision makers, that will surely support the international organizations for reaching the goals of the clear, healthy, peaceful and beautiful minds of the humankind, which will also serve or help for the whole humankind. For instance, the studies that can be organized by help of the multilateral development banks such as the World Bank or the Islamic Development Bank across different countries such as Georgia or Ukraine or continents such as Africa or Asia (see Slides 141 to 143).

\section{Acknowledgements}

I would like to thank to Professor Dr. Marko Bohanec from Jožef Stefan Institute in Slovenia for all of his experience and thoughts sharing, guidance, help and support for the modeling activities in the DEXi in this study. "Great Minds Discuss Ideas, Average Minds Discuss Events, Small Minds Discuss People" Eleanor Roosevelt. 


\section{References}

Abouelnaga, A.E., Metwally, A., Nagy, M.E., \& Agamy, S. (2009). Optimum selection of an energy resource using fuzzy logic. Nuclear Engineering and Design, 239(12), 3062-3068. http://dx.doi.org/10.1016/j.nucengdes.2009.09.002

Alizadeh, S., Ghazanfari, M., \& Fathian, M. (2008). Using data mining for learning and clustering FCM. World Academy of Science, Engineering and Technology, 18, 846-853.

Anderson, T., Doig, A., Khennas, S., \& Rees, D. (1999). Rural energy services a handbook for sustainable energy development. London: Intermediate Technology Cop. http://dx.doi.org/10.3362/9781780443133

Arh, T., \& Blažič, B.J. (2007). Application of multi-attribute decision making approach to learning management systems evaluation. Journal of Computers, 2(10), 28-37. http://dx.doi.org/10.4304/jcp.2.10.28-37

Bohanec, M. (2013). DEXi: Program for multi-attribute decision making user's manual version 4.00. Ljubljana: Jožef Stefan Institute.

Bohanec, M., Bratko, I., \& Rajkovič, V. (1983). An expert system for decision making. In Sol, H.G. (Ed.). Processes and Tools for Decision Making. North-Holland. 235-248.

Bohanec, M., Messean, A., Scatasta, S., Angevin, F., Griffiths, B., Krogh, P.H. et al. (2008). A qualitative multi-attribute model for economic and ecological assessment of genetically modified crops. Ecological Modelling, 215, 147-261. http://dx.doi.org/10.1016/j.ecolmodel.2008.02.016

Bohanec, M., Messéan, A., Scatasta, S., Džeroski, S., \& Žnidaršič, M. (2005). A Qualitative Multi-attribute Model for Economic and Ecological Evaluation of Genetically Modified Crops. Informatics for Environmental Protection - Networking Environmental Information. Masaryk University Brno. 661-668.

Bohanec, M., \& Rajkovič, V. (1990). DEX: An expert system shell for decision support. Sistemica, 1(1), 145-157.

Bohanec, M., \& Rajkovič, V. (1999). Multi-Attribute Decision Modeling: Industrial Applications of DEX. Informatica, 23, 487-491.

Bohanec, M., Žnidaršič, M., Rajkovič, V., Bratko, I., \& Zupan, B. (2013). DEX Methodology: Three Decades of Qualitative Multi-Attribute Modeling. Informatica, 37, 49-54.

Brans, J.P., \& Vincke, P.H. (1985). A preference ranking organisation method: The PROMETHEE method for MCDM. Management Science, 31(6), 647-656. http://dx.doi.org/10.1287/mnsc.31.6.647

Bridgman, P.W. (1922). Dimensional Analysis. New Haven, CT, USA: Yale University Press. 
Castaldi, D., Chastain, E., Windram, M., \& Ziatyk, L. (2003). A study of hydroelectric power: from a global perspective to a local application. College of Earth and Mineral Sciences, The Pennsylvania State University, USA.

Chou, C.C. (2007). A fuzzy MCDM method for solving marine transshipment container port selection problems. Applied Mathematics and Computation, 186, 435-444. http://dx.doi.org/10.1016/j.amc.2006.07.125

Costa, C.A.B., De Corte, J.M., \& Vansnick, J.C. (2012). MACBETH. International Journal of Information Technology \& Decision Making, 11, 359-387. http://dx.doi.org/10.1142/S0219622012400068

Efstathiou, J., \& Rajkovič, V. (1979). Multiattribute decisionmaking using a fuzzy heuristic approach. IEEE Trans. on Systems, Man, and Cybernetics, SMC-9, 326-333. http://dx.doi.org/10.1109/TSMC.1979.4310221

EMRA (Republic of Turkey Energy Market Regulatory Authority) (2013). The data of the Turkish Electrical Energy 10-year Generation Capacity Projection 2003-2012, 2005-2014, 2006-2015, 2007-2016, 2008-2017, 2009-2018, 2010-2019, 2011-2020, and 2012-2021 Reports. http://www.emra.gov.tr/ and http://www.epdk.gov.tr/ (Accessed: January 2013).

Franklin, B. (1972). Benjamin Franklin's 1772 letter to Joseph Priestley. In Bell Jr., W.J., \& Labaree, L.W. (Eds.). Mr. Franklin: A Selection from His Personal Letters. Yale University Press: New Haven, CT 1956. (http://www.procon.org/view.background-resource.php?resourceID=1474)

Gabrys, B., \& Bargiela, A. (2000). General fuzzy min-max neural network for clustering and classification. IEEE transactions on neural networks, 11(3), 769-783. http://dx.doi.org/10.1109/72.846747

Gastwirth, J., Modarres, R., \& Bura, E. (2005). The use of the Lorenz curve, Gini index and related measures of relative inequality and uniformity in securities law. International Journal of Statistics, LXIII(3), 451-469.

GDSHW (General Directorate of State Hydraulic Works) (2013). The data of hydropower plants. http://www.dsi.gov.tr/ (Accessed: January 2013).

Hossain, M.S., \& Das, N.G. (2010). GIS-based multi-criteria evaluation to land suitability modelling for giant prawn (Macrobrachium rosenbergii) farming in Companigonj Upazila of Noakhali, Bangladesh. Computers and Electronics in Agriculture, 70, 172-186. http://dx.doi.org/10.1016/j.compag.2009.10.003

Hwang, C.L., \& Yoon, K. (1981). Multiple Attribute Decision Making: Methods and Applications. New York: Springer-Verlag. http://dx.doi.org/10.1007/978-3-642-48318-9 
IPCC (Intergovernmental Panel On Climate Change) (2014). Climate Change 2013: The Physical Science Basis. http://www.climatechange2013.org/images/report/WG1AR5 ALL FINAL.pdf (Accessed: February 2014).

IRENA (International Renewable Energy Agency) (2014). Data of hydropower plants. http://costing.irena.org/charts/hydropower.aspx (Accessed: February 2013).

Kaya, T., \& Kahraman, C. (2010). Multicriteria renewable energy planning using an integrated fuzzy VIKOR \& AHP methodology: The case of Istanbul. Energy, 35(6), 2517-2527. http://dx.doi.org/10.1016/j.energy.2010.02.051

Kintsch, W., \& Cacioppo, J.T. (1994). Introduction to the 100th anniversary issue of the psycological review. Psychological Review, 101(2), 195-199. http://dx.doi.org/10.1037/0033295X.101.2.195

Kontić, B. (2013). Strategic environmental consideration of nuclear power through comparative evaluation of energy options. Chemical Engineering Transactions, 34, 13-18.

Liao, S.H., Chen, J.L., \& Hsu, T.Y. (2009). Ontology-based data mining approach implemented for sport marketing. Expert Systems with Applications, 36, 11045-11056. http://dx.doi.org/10.1016/j.eswa.2009.02.087

Lin, C.T., \& Juan, P.J. (2009). Developing a hierarchy relation with an expert decision analysis process for selecting the optimal resort type for a Taiwanese international resort park. Expert Systems with Applications, 36, 1706-1719. http://dx.doi.org/10.1016/j.eswa.2007.11.044

Loken, E., Botterud, A., \& Holen, A.T. (2009). Use of the equivalent attribute technique in multi-criteria planning of local energy systems. European Journal of Operational Research, 197(3), 1075-1083. http://dx.doi.org/10.1016/j.ejor.2007.12.050

Lorenz, M.O. (1905). Methods of measuring the concentration of wealth. American Statistical Association, 9(70), 209-219. http://dx.doi.org/10.2307/2276207

Matarazzo, B. (1988). Preference ranking global frequencies in multicriterion analysis (PRAGMA). European Journal of Operational Research, 36(1), 36-49. http://dx.doi.org/10.1016/0377-2217(88)90005-7

Miller, G.A. (1956). The magical number seven, plus or minus two: some limits on our capacity for processing information. The Psychological Review, 63, 81-97. http://dx.doi.org/10.1037/h0043158

Mishra, S., Singal, S.K., \& Khatod, D.K. (2012). A review on electromechanical equipment applicable to small hydropower plants. International Journal Of Energy Research, 36, 553-571. http://dx.doi.org/10.1002/er.1955 
Mokhtarian, M.N., \& Hadi-Vencheh, A. (2012). A new fuzzy TOPSIS method based on left and right scores: An application for determining an industrial zone for dairy products factory. Applied Soft Computing, 12, 2496-2505. http://dx.doi.org/10.1016/j.asoc.2012.03.042

Paish, O. (2002). Small hydro power: technology and current status. Renewable and Sustainable Energy Reviews, 6, 537-556. http://dx.doi.org/10.1016/S1364-0321(02)00006-0

Palumbo, M., Lauro, C.N., \& Greenacre, M.J. (2010). Data Analysis and Classification. Berlin: Springer. http://dx.doi.org/10.1007/978-3-642-03739-9

Po, R.W., Guh, Y.Y., \& Yang, M.S. (2009). A new clustering approach using data envelopment analysis. European Journal of Operational Research, 199, 276-284. http://dx.doi.org/10.1016/j.ejor.2008.10.022

Rojanamon, P., Chaisomphob, T., \& Bureekul, T. (2009). Application of geographical information system to site selection of small run-of-river hydropower project by considering engineering/economic/environmental criteria and social impact. Renewable and Sustainable Energy Reviews, 13(9), 2336-2348. http://dx.doi.org/10.1016/j.rser.2009.07.003

Roy, B. (1991). The outranking approach and the foundations of ELECTRE methods. Theory and Decision, 31, 49-73. http://dx.doi.org/10.1007/BF00134132

Saaty, T.L. (1990). How to make a decision: The Analytic Hierarchy Process. European Journal of Operational Research, 48, 9-26. http://dx.doi.org/10.1016/0377-2217(90)90057-I

Sadok, W., Angevin, F., Bergez, J.E., Bockstaller, C., Colomb, B., Guichard, L. et al. (2009). MASC, a qualitative multi-attribute decision model for ex ante assessment of the sustainability of cropping systems. Agronomy for Sustainable Development, 29, 447-461. http://dx.doi.org/10.1051/agro/2009006

Saracoglu, B.O. (2013). Selecting industrial investment locations in master plans of countries. European Journal Industrial Engineering, 7(4), 416-441. http://dx.doi.org/10.1504/EJIE.2013.055016

Schweickert, R., \& Boruff, B. (1986). Short-term memory capacity: Magic number or magic spell? Journal of Experimental Psychology: Learning, Memory, and Cognition, 12(3), 419-425. http://dx.doi.org/10.1037/0278-7393.12.3.419

Shiffrin, R.M., \& Nosofsky, R.M. (1994). Seven plus or minus two: a commentary on capacity limitations. Psychological Review, 101(2), 357-361. http://dx.doi.org/10.1037/0033-295X.101.2.357

Supriyasilp, T., Pongput, K., \& Boonyasirikul, T. (2009), Hydropower development priority using MCDM method. Energy Policy, 37(5), 1866-1875. http://dx.doi.org/10.1016/j.enpol.2009.01.023 
Strehl, A., \& Ghosh, J. (2002). Cluster ensembles - a knowledge reuse framework for combining multiple partitions. Journal of Machine Learning Research, 3, 583-617.

Taškova, K., Stojanova, D., Bohanec, M., \& Džeroski, S. (2007). A qualitative decision-support model for evaluating researchers. Informatica, 31, 479-486.

Trebuňa, P., \& Halčinová, J. (2013). Mathematical tools of cluster analysis. Applied Mathematics, 4, 814-816. http://dx.doi.org/10.4236/am.2013.45111

TEIAS (Turkish Electricity Transmission Corporation) (2013). The data of the Turkish Electrical Energy 10-year Generation Capacity Projection 2003-2012, 2005-2014, 2006-2015, 2007-2016, 2008-2017, 2009-2018, 2010-2019, 2011-2020, and 2012-2021 Reports. http://www.teias.gov.tr/ (Accessed: January 2013).

Voros, N.G., Kiranoudis, C.T., \& Maroulis, Z.B. (1999). Short-cut design of small hydroelectric plants. Renewable Energy, 19, 545-563. http://dx.doi.org/10.1016/S0960-1481(99)00083-X

Vucijak, B., Kupusovic, T., Midzic-Kurtagic, S., \& Ceric, A. (2013). Applicability of multicriteria decision aid to sustainable hydropower. Applied Energy, 101, 261-267. http://dx.doi.org/10.1016/j.apenergy.2012.05.024

Worldbank (2014). http://www.worldbank.org/ (Accessed: January 2014).

Weaver, T. (2012). Financial appraisal of operational offshore wind energy projects. Renewable and Sustainable Energy Reviews. 16, 5110-5120. http://dx.doi.org/10.1016/j.rser.2012.05.003

Wu, K.L., \& Yang, M.S. (2002). Alternative c-means clustering algorithms. Pattern Recognition. 35, 2267-2278. http://dx.doi.org/10.1016/S0031-3203(01)00197-2

Journal of Industrial Engineering and Management, 2016 (www.jiem.org)

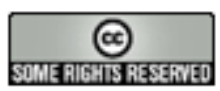

Article's contents are provided on an Attribution-Non Commercial 3.0 Creative commons license. Readers are allowed to copy, distribute and communicate article's contents, provided the author's and Journal of Industrial Engineering and Management's names are included. It must not be used for commercial purposes. To see the complete license contents, please visit http://creativecommons.org/licenses/by-nc/3.0/. 